\title{
Aortic Dissection after Percutaneous Coronary Intervention for Acute Coronary Syndrome: An Outcomes-Based Study from the Nationwide Inpatient Sample Database
}

\author{
Christine S. M. Lau ${ }^{1,2}$, Georgia J. McRoy ${ }^{2}$, Krishnaraj Mahendraraj', Kedar P. Kulkarni1,2, \\ Ronald S. Chamberlain $1,2,3,4^{*}$ \\ ${ }^{1}$ Department of Surgery, Saint Barnabas Medical Center, Livingston, NJ, USA \\ ${ }^{2}$ School of Medicine, Saint George's University, St. George, Grenada \\ ${ }^{3}$ Department of Surgery, New Jersey Medical School, Rutgers University, Newark, NJ, USA \\ ${ }^{4}$ Department of Surgery, Banner MD Anderson Cancer Center, Gilbert, AZ, USA \\ Email: *Ronald.Chamberlain@bannerhealth.com
}

How to cite this paper: Lau, C.S.M., McRoy, G.J., Mahendraraj, K., Kulkarni, K.P. and Chamberlain, R.S. (2017) Aortic Dissection after Percutaneous Coronary Intervention for Acute Coronary Syndrome: An Outcomes-Based Study from the Nationwide Inpatient Sample Database. International Journal of Clinical Medicine, 8, 21-33. http://dx.doi.org/10.4236/ijcm.2017.81003

Received: December 6, 2016

Accepted: January 19, 2017

Published: January 22, 2017

Copyright $\odot 2017$ by authors and Scientific Research Publishing Inc. This work is licensed under the Creative Commons Attribution International License (CC BY 4.0).

http://creativecommons.org/licenses/by/4.0/

\begin{abstract}
Introduction: Aortic dissection is a rare complication of Percutaneous Coronary Intervention (PCI) for Acute Coronary Syndrome (ACS), but is associated with mortality rates of up to $20 \%$. This study assessed the demographic and clinical profile of a large cohort of patients undergoing PCI for ACS to assess patient and clinical risk factors that may predispose to the development of aortic dissection. Methods: The Nationwide Inpatient Sample (NIS) database (20012011) was used to abstract admission data on patients undergoing PCI for ACS. Results: 777,595 patients underwent PCI and 380 (0.05\%) developed aortic dissection. Patients who developed aortic dissection were more often older (68 vs. 64 years), female ( $47.4 \%$ vs. $33.8 \%$ ), insured through Medicare $(56.2 \%$ vs. $50.7 \%$ ), Medicaid (7.9\% vs. $5.3 \%$ ) or uninsured/self-pay (6.3\% vs. $4.7 \%), p<$ 0.05 . Patients with aortic dissection had a higher rate of ventricular fibrillation (6.3\% vs. $1.8 \%)$, cerebrovascular accident ( $2.4 \%$ vs. $0.4 \%)$, longer lengths of hospitalization ( 9 days vs. 3 days), as well as higher mortality (13.2\% vs. $1.4 \%), p$ $<0.001$. Multivariate analysis identified female gender, Hispanic race, uninsured/self-pay, fluid and electrolyte disorders, and peripheral vascular disease (PVD) as independent risk factors for aortic dissection after PCI. Conclusion: Aortic dissection is a rare complication of PCI, which occurs more often in older patients with Medicare insurance status. Hispanics, females, uninsured patients and those with PVD are at the highest risk of aortic dissection. Clinicians should be more cognizant of patients at increased risk of developing PCI in order to institute earlier screening in high-risk patients.
\end{abstract}




\section{Keywords}

Aortic Dissection, Percutaneous Coronary Intervention, NIS

\section{Introduction}

Percutaneous Coronary Intervention (PCI) is widely recognized as an effective treatment for Acute Coronary Syndrome (ACS), and over half a million PCI procedures are performed each year in the United States (US) [1]. Despite significant advances and extensive individual experience with interventional cardiology procedures, aortic dissection remains a rare complication. Aortic dissection occurs with an estimated incidence of $<0.1 \%$ following PCI procedures, and is associated with increased in-hospital mortality $(20 \%-50 \%)$ as well as other severe complications [2] [3] [4] [5].

Given its rarity, current knowledge regarding which patient risk factors are associated with an increased occurrence of aortic dissection following PCI remains limited. At present, only scant data on risk factors associated with aortic dissection following PCI exist and are limited primarily to single case studies or small retrospective cohort studies, which makes it of little value in risk stratifying or predicting which patients are at risk.

This current study examines a large cohort of patients undergoing PCI for ACS from the Nationwide Inpatient Sample (NIS) database in an effort to identify demographic and clinical factors which relate to the occurrence of aortic dissection following PCI.

\section{Methods}

Data for the current study was extracted from the NIS database, a part of the Healthcare Cost and Utilization Project (HCUP) of the Agency for Healthcare Research and Quality (AHRQ) database, over an eleven-year period (20012011). The NIS is the largest all-payer inpatient care database in the US, containing data on more than eight million hospital stays from over 1000 hospitals. 777,595 patients underwent PCI for ACS were identified and exported to IBM SPSS $^{\circledR}$ v20.2. ACS was defined as ST-elevation myocardial infarction (STEMI), non-ST-elevation myocardial infarction (NSTEMI), and unstable angina. PCI as a primary procedure was identified using ICD9 code 36.06. Acute myocardial infarction (MI) was identified using ICD-9-CM code 410 and unstable angina with 411.1. Demographic and clinical information pertaining to patient age, gender, race, admission source, primary expected payer, indication for PCI, and preexisting comorbidities was extracted. Endpoints examined included length of stay (LOS), serious complications including Dressler's syndrome, sepsis, cerebrovascular accidents (CVA), and ventricular fibrillation, as well as overall inpatient mortality. Patients who develop aortic dissection were identified using ICD-9-CM code 441.0. The ICD-9-CM codes used to identify complication rates 
were 411.0 for post-MI syndrome (Dressler's syndrome), 995.91 for sepsis, 434.91 for cerebrovascular accident, and 427.41 for ventricular fibrillation. Demographic and clinical characteristics as well as patient outcomes were compared across the two subgroups: patients who developed aortic dissection and those who did not. Categorical variables were compared using the Chi-square test, while continuous variables were compared using student $\mathrm{t}$-test and analysis of variance (ANOVA). Multivariate analysis using the "backward Wald" method was performed to calculate odds ratios (OR) and determine independent factors which increased the risk of developing aortic dissection following PCI. All reported data was included in the calculations and analysis, including frequency and multivariate analysis. Any missing and unknown data were excluded. A $p$-value of $<0.05$ was utilized to determine statistical significance.

The current study was approved by the Saint Barnabas Medical Center Ethics Board. This is a retrospective study using data extracted from the NIS database. No specific patient identifiable information was utilized, and no patient consent form was required.

\section{Results}

777,595 patients underwent PCI for ACS as reported in the NIS database over the 11-year study period (2001-2011) (Table 1). There were 380 patients who experienced aortic dissection (0.05\%) and 777,215 patients who did not (99.95\%).

\subsection{Demographic Characteristics}

The mean age for all patients who underwent PCI for ACS was $64 \pm 12$ years (Table 1). Patients who developed aortic dissection after PCI had a significantly higher mean age (68 \pm 12 years) than those who did not develop aortic dissection (64 \pm 12 years), $p<0.001$. A greater proportion of patients who developed aortic dissection after PCI were $\geq 65$ years old ( $60.5 \%$ vs. $50.5 \%, p<0.001)$, while a lower percentage of patients developing aortic dissection after PCI were $<50$ years old $(7.4 \%$ vs. $12.1 \%, p=0.004)$ or between 50 and 64 years old $(32.1 \%$ vs. $37.4 \%, p=0.004)$. The majority of patients who developed aortic dissection were males (52.6\%) with a male:female (M:F) ratio of $1.11: 1, p<0.001$. While the majority of patients who did not develop aortic dissection were also males (66.2\%), there was a significantly greater male preponderance with a M:F ratio of 1.96:1, $p$ $<0.001$. Among those who developed aortic dissection, $75.5 \%(\mathrm{~N}=234)$ were Caucasian, 9.4\% ( $\mathrm{N}=29)$ were African American, 9.7\% $(\mathrm{N}=30)$ were Hispanic, and $5.5 \%(\mathrm{~N}=17)$ were designated as "other".

Overall, most patients who underwent PCI were admitted from the emergency room (ER) (34.2\%) or transferred from another hospital (13.9\%). A significantly greater proportion of patients who developed aortic dissection were admitted from the ER $(41.5 \%$ vs. $34.2 \%, p=0.013)$, compared to those who did not develop aortic dissection.

The majority of patients undergoing PCI for ACS had Medicare as primary 
Table 1. Demographic Profile of 777,595 Acute Coronary Syndrome Patients Undergoing Percutaneous Coronary Intervention (380 Patients who develop Aortic Dissection and 777,215 Patients who did not develop Aortic Dissection) from the Nationwide Inpatient Sample (NIS) Database (2001-2011).

\begin{tabular}{|c|c|c|c|c|}
\hline Variables & Overall & $\begin{array}{c}\text { Aortic } \\
\text { Dissection }\end{array}$ & $\begin{array}{l}\text { No Aortic } \\
\text { Dissection }\end{array}$ & ${ }^{*} p$-value \\
\hline Total, N (\%) & 777,595 (100.0\%) & $380(0.05 \%)$ & 777,215 (99.95\%) & \\
\hline Age, $($ Mean \pm SD $)$ & $64 \pm 12$ & $68 \pm 12$ & $64 \pm 12$ & $<0.001$ \\
\hline Under 50 & $94,364(12.1 \%)$ & $28(7.4 \%)$ & $94,336(12.1 \%)$ & 0.004 \\
\hline Age 50 to 64 & $290,770(37.4 \%)$ & $122(32.1 \%)$ & $290,648(37.4 \%)$ & 0.004 \\
\hline Age 65 and older & $392,429(50.5 \%)$ & $230(60.5 \%)$ & $392,199(50.5 \%)$ & $<0.001$ \\
\hline \multicolumn{5}{|l|}{ Gender } \\
\hline Male & $514,488(66.2 \%)$ & $200(52.6 \%)$ & $514,288(66.2 \%)$ & $<0.001$ \\
\hline Female & $263,071(33.8 \%)$ & $180(47.4 \%)$ & $262,891(33.8 \%)$ & $<0.001$ \\
\hline \multicolumn{5}{|l|}{ Race, N (\%) } \\
\hline Caucasian & $481,994(79.1 \%)$ & $234(75.5 \%)$ & $481,760(79.1 \%)$ & 0.870 \\
\hline African American & $47,293(7.8 \%)$ & $29(9.4 \%)$ & $47,264(7.8 \%)$ & 0.924 \\
\hline Hispanic & $40,617(6.7 \%)$ & $30(9.7 \%)$ & $40,587(6.7 \%)$ & 0.337 \\
\hline Other & $39,230(6.4 \%)$ & $17(5.5 \%)$ & $39,213(6.4 \%)$ & 0.598 \\
\hline \multicolumn{5}{|l|}{ Admission source, $\mathrm{N}(\%)$} \\
\hline ER & $152,650(34.2 \%)$ & $88(41.5 \%)$ & $152,562(34.2 \%)$ & 0.013 \\
\hline Another hospital source & $62,037(13.9 \%)$ & $37(17.5 \%)$ & $62,000(13.9 \%)$ & 0.102 \\
\hline $\begin{array}{l}\text { Other health facility, } \\
\text { including long-term care }\end{array}$ & $12,672(2.8 \%)$ & $8(3.8 \%)$ & $12,664(2.8 \%)$ & 0.378 \\
\hline Court/Law enforcement & $420(0.1 \%)$ & $0(0.0 \%)$ & $420(0.1 \%)$ & \\
\hline $\begin{array}{l}\text { Routine, including births } \\
\text { and other sources }\end{array}$ & $218,318(48.9 \%)$ & $79(37.3 \%)$ & $218,239(48.9 \%)$ & 0.002 \\
\hline \multicolumn{5}{|l|}{$\begin{array}{l}\text { Primary expected payer, } \\
\qquad \mathrm{N}(\%)\end{array}$} \\
\hline Medicare & $393,835(50.7 \%)$ & $213(56.2 \%)$ & $393,622(50.7 \%)$ & 0.033 \\
\hline Medicaid & $41,123(5.3 \%)$ & $30(7.9 \%)$ & $41,093(5.3 \%)$ & 0.023 \\
\hline Private insurance & $278,791(35.9 \%)$ & $97(25.6 \%)$ & $278,694(35.9 \%)$ & $<0.001$ \\
\hline Uninsured/Self pay & $36,760(4.7 \%)$ & $24(6.3 \%)$ & $36,736(4.7 \%)$ & $<0.001$ \\
\hline No charge & $3577(0.5 \%)$ & $1(0.3 \%)$ & $3576(0.5 \%)$ & 0.571 \\
\hline Other & $22,302(2.9 \%)$ & $14(3.7 \%)$ & $22,288(2.9 \%)$ & 0.338 \\
\hline
\end{tabular}

Abbreviations: $\mathrm{ER}=$ emergency room; $\mathrm{N}=$ number; $\mathrm{SD}=$ standard deviation; ${ }^{*} p$-value $<0.05$ was considered statistically significant. 
insurance $(50.7 \%)$, followed by private insurance $(35.9 \%)$. More patients who developed aortic dissection were insured by Medicare (56.2\% vs. $50.7 \%, p=$ $0.033)$, Medicaid ( $7.9 \%$ vs. $5.3 \%, p=0.023)$, or uninsured/self-paying $(6.3 \%$ vs. $4.7 \%, p<0.001)$.

\subsection{Clinical Characteristics}

The most common indication for PCI was unstable angina (41.3\%), followed by STEMI (36.3\%), and NSTEMI (22.4\%) (Table 2). More patients who developed aortic dissection had PCI done for unstable angina ( $48.4 \%$ vs. $41.3 \%, p=0.005$ ).

A greater percentage of patients who developed aortic dissection had preexisting comorbidities, such as peripheral vascular disease (PVD) (91.8\% vs. 10.4\%,

Table 2. Clinical Profile of 777,595 Acute Coronary Syndrome Patients Undergoing Percutaneous Coronary Intervention (380 Patients who develop Aortic Dissection and 777,215 Patients who did not develop Aortic Dissection) from the Nationwide Inpatient Sample (NIS) Database (2001-2011).

\begin{tabular}{|c|c|c|c|c|}
\hline Variables & Overall & $\begin{array}{c}\text { Aortic } \\
\text { Dissection }\end{array}$ & $\begin{array}{l}\text { No Aortic } \\
\text { Dissection }\end{array}$ & ${ }^{*} p$-value \\
\hline Total, N (\%) & $777,595(100.0 \%)$ & $380(0.05 \%)$ & 777,215 (99.95\%) & \\
\hline \multicolumn{5}{|l|}{ Indication, $\mathrm{N}(\%)$} \\
\hline STEMI & $282,475(36.3 \%)$ & $123(32.4 \%)$ & $282,352(36.3 \%)$ & 0.109 \\
\hline NSTEMI & $173,877(22.4 \%)$ & $73(19.2 \%)$ & $173,804(22.4 \%)$ & 0.140 \\
\hline Unstable angina & $321,243(41.3 \%)$ & $184(48.4 \%)$ & $321,059(41.3 \%)$ & 0.005 \\
\hline \multicolumn{5}{|l|}{ Comorbidity, N (\%) } \\
\hline Anemia & $59,054(7.6 \%)$ & $64(16.8 \%)$ & $58,990(7.6 \%)$ & $<0.001$ \\
\hline Congestive heart failure & $6898(0.9 \%)$ & $9(2.4 \%)$ & $6889(0.9 \%)$ & 0.002 \\
\hline Chronic pulmonary disease & $117,106(15.1 \%)$ & $87(22.9 \%)$ & $117,019(15.1 \%)$ & $<0.001$ \\
\hline Depression & $39,284(5.1 \%)$ & $25(6.6 \%)$ & $39,259(5.1 \%)$ & 0.171 \\
\hline Diabetes, uncomplicated & $224,635(28.9 \%)$ & $69(18.2 \%)$ & $224,566(28.9 \%)$ & $<0.001$ \\
\hline $\begin{array}{l}\text { Diabetes, with chronic } \\
\text { complications }\end{array}$ & $27,607(3.6 \%)$ & $15(3.9 \%)$ & $27,592(3.6 \%)$ & 0.676 \\
\hline Hypertension & $537,983(69.2 \%)$ & $262(68.9 \%)$ & $537,721(69.2 \%)$ & 0.920 \\
\hline Hypothyroid & $57,658(7.4 \%)$ & $37(9.7 \%)$ & $57,621(7.4 \%)$ & 0.084 \\
\hline Fluid and electrolyte disorder & $62,827(8.1 \%)$ & $74(19.5 \%)$ & $62,753(8.1 \%)$ & $<0.001$ \\
\hline Obesity & $87,925(11.3 \%)$ & $33(8.7 \%)$ & $87,892(11.3 \%)$ & 0.106 \\
\hline Peripheral vascular disease & $80,865(10.4 \%)$ & $349(91.8 \%)$ & $80,516(10.4 \%)$ & $<0.001$ \\
\hline Renal failure & $72,307(9.3 \%)$ & $61(16.1 \%)$ & $72,246(9.3 \%)$ & $<0.001$ \\
\hline
\end{tabular}

Abbreviations: $\mathrm{N}=$ number; NSTEMI = non-ST-elevation myocardial infarction; ${ }^{*} p$-value $<0.05$ was considered statistically significant; STEMI = ST-elevation myocardial infarction. 
$p<0.001$ ), fluid and electrolyte disorders (19.5\% vs. $8.1 \%, p<0.001)$, anemia ( $16.8 \%$ vs. $7.6 \%, p<0.001)$, congestive heart failure $(2.4 \%$ vs. $0.9 \%, p=0.002)$, chronic pulmonary disease $(22.9 \%$ vs. $15.1 \%, p<0.001)$, and renal failure $(16.1 \%$ vs. $9.3 \%, p<0.001)$. In contrast, there were fewer patients with a history of uncomplicated diabetes $(18.2 \%$ vs. $28.9 \%, p<0.001)$.

\subsection{Clinical Outcomes}

Patients who developed aortic dissection had a longer LOS, compared to those who did not ( $9 \pm 12$ days vs. $3 \pm 4$ days, $p<0.001$ ) (Table 3 ). Serious complications such as Dressler's syndrome (0.2\%), sepsis $(0.7 \%)$, and CVA $(0.4 \%)$, were rare following PCI, however a greater percentage of patients who developed aortic dissection developed sepsis $(2.9 \%$ vs. $0.7 \%, p<0.001)$, CVA $(2.4 \%$ vs. $0.4 \%, p$ $<0.001)$, and ventricular fibrillation (6.3\% vs. $1.8 \%, p<0.001)$.

The overall in-hospital mortality was significantly higher among patients who developed aortic dissection (13.2\% vs. $1.4 \%, p<0.001)$.

\subsection{Multivariate Analysis}

Multivariate analysis identified female gender (OR 1.5), Hispanic race (OR 1.9), uninsured/self-pay (OR 2.4), electrolyte disorders (OR 1.5), and PVD (OR 129.2) as independent risk factors for developing aortic dissection following PCI, $p<$ 0.05 .

Table 3. Clinical Outcome Profile of 777,595 Acute Coronary Syndrome Patients Undergoing Percutaneous Coronary Intervention (380 Patients who develop Aortic Dissection and 777,215 Patients who did not develop Aortic Dissection) from the Nationwide Inpatient Sample (NIS) Database (2001-2011).

\begin{tabular}{ccccc}
\hline Variables & Overall & Aortic Dissection & $\begin{array}{c}\text { No Aortic } \\
\text { Dissection }\end{array}$ & ${ }^{*} p$-value \\
\hline $\begin{array}{c}\text { Total, N (\%) } \\
\text { Length of stay } \\
\text { (mean days } \pm \text { SD) }\end{array}$ & $377,595(100.0 \%)$ & $380(0.05 \%)$ & $777,215(99.95 \%)$ & \\
$\begin{array}{c}\text { Serious complication, N (\%) } \\
\text { Dressler's syndrome }\end{array}$ & $1404(0.2 \%)$ & $1(0.3 \%)$ & $1403(0.2 \%)$ & 0.704 \\
Sepsis & $5221(0.7 \%)$ & $11(2.9 \%)$ & $5210(0.7 \%)$ & $<0.001$ \\
CVA & $3465(0.4 \%)$ & $9(2.4 \%)$ & $3456(0.4 \%)$ & $<0.001$ \\
Ventricular fibrillation & $14,337(1.8 \%)$ & $24(6.3 \%)$ & $14,313(1.8 \%)$ & $<0.001$ \\
Outcome of hospitalization, \\
N (\%)
\end{tabular}

Abbreviations: $\mathrm{CVA}=$ cerebrovascular accident; $\mathrm{N}=$ number; $\mathrm{SD}=$ standard deviation; ${ }^{\star} p$-value $<0.05$ was considered statistically significant. 


\section{Discussion}

Aortic dissection is a rare complication following PCI. Although PCI was not performed until 1977, iatrogenic aortic dissection following open-heart surgery was first reported in the 1960s [6] [7]. In a recent single-center retrospective study over a 14-year period published by Leontyev et al. (2012), the incidence of iatrogenic aortic dissection was reported to be $0.06 \%$ following other cardiac surgical procedures and $0.01 \%$ following cardiac catheterization procedures [3]. In the current study, aortic dissections occurred in $0.05 \%$ of the PCI cases following ACS with an in-house mortality of $13.2 \%$. These results are consistent with more recent PCI studies, which have reported incidence rates ranging from $0.02 \%$ to $0.07 \%$, with mortality rates as high as $50 \%$ [8] [9] [10] [11] [12]. Patients who develop aortic dissections following PCI had longer lengths of hospitalization and lower survival rates. Moreover, these patients were more likely to have other serious complications associated with PCI, including sepsis, CVA, and ventricular fibrillation. Although a rare complication; the incidence and clinical implications of aortic dissection after PCI warrants further investigation given the high mortality rate and the growing number of cardiovascular intervention procedures performed [3] [4] [5]. This is the largest retrospective cohort study to delineate the demographic and risk factors among PCI patients who develop aortic dissection.

The exact mechanism of aortic dissection following PCI remains unclear; however, several possible mechanisms have been proposed, with the most common being retrograde propagation of a coronary dissection secondary to mechanical trauma of a wire, catheter, balloon inflation, or another interventional device and trauma resulting from the guiding catheter itself [2] [12] [13]. Previous studies have shown an association between atherosclerosis and heavily calcified vessels with increased risk of catheter-induced aortic dissection [2] [14] [15] [16]. The relationship between the role of atherosclerosis and the velocity of the retrograde flow, more specifically a forceful contrast injection into the false lumen, has been suggested as an additional or concurrent mechanism for aortic dissection following PCI [10]. A high velocity retrograde jet may disrupt diseased intima at the tip of the cannula at the time of cannulation or later during the perfusion [7].

Aortic dissection after PCI is more prevalent in patients $>65$ years old. This data is consistent with several studies on aortic dissection, which have reported older age as a risk factor [17] [18]. In addition, there were a greater proportion of females, African Americans, and Hispanics who developed aortic dissection after PCI. Females and Hispanics were at a 1.5 and 1.9 times greater risk of developing aortic dissection following PCI. This is in contrast to a retrospective study by Nienbaber et al. involving 1078 patients enrolled in the International Registry of Acute Aortic Dissection (IRAD), which reported that aortic dissections were less frequent in females, however, females who did develop aortic dissection were significantly older than men [19]. These findings suggest there should be a greater suspicion for the possibility of aortic dissection following 
PCI in these high-risk patients.

In addition to age and gender, the implication of PVD in the incidence of aortic dissection following PCI has been discussed. Patients with PVD had a 129.2 times higher chance of developing aortic dissection. In a study of 48 patients who developed aortic dissection following PCI by Leontyev et al., $22.9 \%$ of patients had a history of PVD [3]. In addition to PVD being a risk factor for aortic dissection, $47.9 \%$ of patients had New York Heart Association (NYHA) class III/IV symptoms, and $33.3 \%$ of patients had a left ventricular ejection fraction (LVEF) $<50 \%$ [3]. Multivariate analysis indicated coronary malperfusion and preoperative NYHA class IV symptoms as being independently associated with early mortality [3].

Diagnostic imaging for aortic dissection is used to rapidly confirm or exclude the diagnosis, and classify the extent of the dissection. Computed tomography (CT) is used in $61 \%$ of cases, while echocardiogram is used in $33 \%$, magnetic resonance imaging (MRI) in 4\%, and aortography in 4\% [14] [20] [21]. Transthoracic echocardiography (TTE) can be beneficial in identifying proximal aortic dissections in emergent cases with unstable patients, and confirmation of the diagnosis often requires more than one non-invasive imaging study [14].

In addition to current imaging, the diagnostic biomarkers which permit the early detection of aortic dissection have been investigated. Circulating smooth muscle myosin heavy chain protein, which is released from damaged medial smooth muscle of the aorta, has been shown to be elevated in the initial hours of an acute dissection [14] [22]. In a review studying the circulating biomarkers available for the diagnosis and prognosis stratification of aortic dissection, Morello et al. (2014) reported that the variation in the range of biomarkers of aortic dissection could potentially be used as a tool to screen symptomatic patients, to identify patients at higher risk of aortic disease, to rule out aortic dissection with low clinical probability of aortic dissection and/or to obtain prognostic stratification of affected patients [22]. Acute phase reactors such as C-reactive protein, fibrinogen, D-dimer, and soluble elastin fragments have all been evaluated and serve as additional diagnostic tools in determining disease extent and progression [14] [22] [23].

Treatment of acute aortic dissections typically involves both medical and surgical management, depending upon the location of the dissection. Treatment choice is determined based on patient stability, nature of the dissection involving the coronary artery, and extent of aortic dissection [2]. Dissections involving the ascending aorta are surgical emergencies requiring quick open or endovascular repair and reconstruction to improve prognosis [14]. In contrast, dissections involving the descending aorta can be treated medically unless there are indications of progression of the dissection, intractable pain, organ malperfusion, or extra-aortic blood is demonstrated [14] [20]. While surgical resection or stenting of the ascending aorta and possibly the aortic arch is considered the gold standard treatment for dissections involving the ascending aorta; this has also been extended to patients with iatrogenic aortic dissections [24]. 
In this study, aortic dissections occurred most often following PCI for unstable angina compared to STEMI and NSTEMI. The decrease in incidence and mortality rate after aortic dissection following PCI reported in the current study may be attributable to improved recognition of aortic dissection as a complication after PCI and advancements in PCI procedures [3]. Drug-eluting stents, have been shown to significantly reduce the rate of in-stent revascularization, but has been associated with increased rates of late stent thrombosis [25]. Bengalore et al. (2013) completed a meta-analysis, which included 28 randomized control trials with 34,068 patients, evaluating the long-term efficacy and safety of drug-eluting stents versus bare-metal stents in patients with STEMI. Results showed that drug-eluting stents reduced the risk of total vessel revascularization by over 30\% without increasing the rate of adverse events [26]. Leontyev et al. estimated a mean survival of $4.3 \pm 0.9$ years, and survival at 1-, 3-, and 5-year post-iatrogenic aortic dissection repair to be $43 \% \pm 7 \%, 40 \% \pm 4 \%$, and $40 \% \pm$ $7 \%$, respectively [3]. Hence, the continuation of advancements in the area of PCI and ACS treatment coupled with the identification of risk factors associated with aortic dissection following PCI are critical to improve the prognosis of the patient population at risk.

Given the retrospective nature of this study, the current study has several limitations which are inherent to large administrative databases, including sampling and coding errors. Complications occurring immediately following the procedure were reported in the NIS database; however, readmissions for a complication of undergoing PCI were not identifiable, potentially underestimating the actual complication rates. These limitations however, would apply to all groups and therefore should not have affected the overall results of this study. This limitation to in-hospital information without follow-up data could lead to long-term complications and mortality after hospital discharge not being captured in this study. Data regarding specific procedural characteristics, the specific and extent of each vessel involvement, vascular access route, catheters used, and operator experience was also lacking. Furthermore, the presence of comorbidities was based on the presence of administrative codes within the NIS database and was not clinically confirmed. Participation in the NIS database is voluntary, and only selected centers participate in the registry. Further, there is no information regarding the method of diagnosing aortic dissection, the location and extent of dissection, whether or not the carotid artery was dissected, timing of surgery relative to the qualifying event, and the management or medications given to the patients. Despite these limitations however, the NIS includes data from 1000 different hospitals in the US and more than 700,000 patient records were obtained for this study, and is likely a diverse enough sample to be able to generalize across most US hospitals in terms of delivery of care.

\section{Conclusion}

Aortic dissection is a rare but potentially lethal complication after PCI for ACS, which occurs most commonly in older patients admitted from the ER with Me- 
dicaid insurance. Aortic dissection is associated with significantly worse outcomes including longer lengths of stay, and higher rates of mortality, ventricular fibrillation, sepsis, and CVA. Hispanics, females, uninsured/self-paying patients and those with electrolyte disorders or PVD are at the highest risk of aortic dissection. Despite new advances in diagnosing and aggressive and timely treatment, aortic dissection after PCI is associated with significant morbidity and mortality. This report represents the largest published study to examine trends in demographic and clinical profiles of patients who develop aortic dissection following PCI. The current study gives insight into the existing risk factors, which predisposes patients to the development of aortic dissection after PCI. In addition, the implications of aggressive manipulation of a guide catheter along with high velocity retrograde flow should be stressed to operators as significant factors in the incidence of aortic dissection after PCI in the population at risk. Knowledge of key diagnostic biomarkers and imaging studies is necessary to facilitate the urgent diagnosis and treatment of aortic dissection following PCI and to prevent morbidity and mortality. Clinicians should be more cognizant of patients at increased risk of developing aortic dissection in order to institute earlier screening in high-risk patients.

\section{References}

[1] Marso, S.P., Teirstein, P.S., Kereiakes, D.J., Moses, J., Lasala, J. and Grantham, J.A. (2012) Percutaneous Coronary Intervention Use in the United States: Defining Measures of Appropriateness. JACC: Cardiovascular Interventions, 5, 229-235. https://doi.org/10.1016/j.jcin.2011.12.004

[2] Noguchi, K., Hori, D., Nomura, Y. and Tanaka, H. (2012) Iatrogenic Acute Aortic Dissection during Percutaneous Coronary Intervention for Acute Myocardial Infarction. Annals of Vascular Diseases, 5, 78-81. https://doi.org/10.3400/avd.cr.11.00057

[3] Leontyev, S., Borger, M.A., Legare, J.F., et al. (2012) Iatrogenic Type A Aortic Dissection during Cardiac Procedures: Early and Late Outcome in 48 Patients. European Journal of Cardio- Thoracic Surgery, 41, 641-646. https://doi.org/10.1093/ejcts/ezr070

[4] Still, R.J., Hilgenberg, A.D., Akins, C.W., Daggett, W.M. and Buckley, M.J. (1992) Intraoperative Aortic Dissection. The Annals of Thoracic Surgery, 53, 374-379. https://doi.org/10.1016/0003-4975(92)90254-2

[5] Fleck, T., Ehrlich, M., Czerny, M., Wolner, E., Grabenwoger, M. and Grimm, M. (2006) Intraoperative Iatrogenic Type A Aortic Dissection and Perioperative Outcome. Interactive Cardiovascular and Thoracic Surgery, 5, 11-14. https://doi.org/10.1510/icvts.2005.114900

[6] Gruentzig, A.R., King III, S.B., Schlumpf, M. and Siegenthaler, W. (1987) LongTerm Follow-Up after Percutaneous Transluminal Coronary Angioplasty. The Early Zurich Experience. The New England Journal of Medicine, 316, 1127-1132. https://doi.org/10.1056/NEJM198704303161805

[7] Matar, A.F. and Ross, D.N. (1967) Traumatic Arterial Dissection in Open-Heart Surgery. Thorax, 22, 82-87. https://doi.org/10.1136/thx.22.1.82

[8] Dunning, D.W., Kahn, J.K., Hawkins, E.T. and O’Neill, W.W. (2000) Iatrogenic Coronary Artery Dissections Extending into and Involving the Aortic Root. Cathe- 
terization and Cardiovascular Interventions, 51, 387-393. https://doi.org/10.1002/1522-726X(200012)51:4<387::AID-CCD3>3.0.CO;2-B

[9] Wyss, C.A., Steffel, J. and Luscher, T.F. (2008) Isolated Acute Iatrogenic Aortic Dissection during Percutaneous Coronary Intervention without Involvement of the Coronary Arteries. Journal of Invasive Cardiology, 20, 380-382.

[10] Welch, T.D., Foley, T., Barsness, G.W., et al. (2012) Iatrogenic Aortic Dissection... or Intramural Hematoma? Circulation, 125, e415-e418. https://doi.org/10.1161/CIRCULATIONAHA.111.056937

[11] Boyle, A.J., Chan, M., Dib, J. and Resar, J. (2006) Catheter-Induced Coronary Artery Dissection: Risk Factors, Prevention and Management. Journal of Invasive Cardiology, 18, 500-503.

[12] Perez-Castellano, N., Garcia-Fernandez, M.A., Garcia, E.J. and Delcan, J.L. (1998) Dissection of the aortic sinus of Valsalva complicating coronary catheterization: cause, mechanism, evolution, and management. Catheterization and Cardiovascular Interventions, 43, 273-279. https://doi.org/10.1002/(SICI)1097-0304(199803)43:3<273::AID-CCD7>3.0.CO;2-6

[13] Yip, H.K., Wu, C.J., Yeh, K.H., et al. (2001) Unusual Complication of Retrograde Dissection to the Coronary Sinus of Valsalva during Percutaneous Revascularization: A Single-Center Experience and Literature Review. Chest, 119, 493-501. https://doi.org/10.1378/chest.119.2.493

[14] Uyan, C., Arinc, H., Gunduz, H. and Akdemir, R. (2008) Dissection of the Ascending Thoracic Aorta as a Complication of Percutaneous Coronary Intervention. Vascular Health and Risk Managemen, 4, 253-257. https://doi.org/10.2147/VHRM.S2218

[15] Doyle, B. and Juergens, C.P. (2004) Conservative Management of Ascending Aortic Dissection Caused by Percutaneous Coronary Intervention. Journal of Invasive Cardiology, 16, 92-94.

[16] Januzzi, J.L., Sabatine, M.S., Eagle, K.A., et al. (2002) Iatrogenic Aortic Dissection. American Journal of Cardiology, 89, 623-626. https://doi.org/10.1016/S0002-9149(01)02312-8

[17] Larson, E.W. and Edwards, W.D. (1984) Risk Factors for Aortic Dissection: A Necropsy Study of 161 Cases. American Journal of Cardiology, 53, 849-855. https://doi.org/10.1016/0002-9149(84)90418-1

[18] Spittell, P.C., Spittell, J.A., Joyce, J.W., et al. (1993) Clinical Features and Differential Diagnosis of Aortic Dissection: Experience with 236 Cases (1980 through 1990). Mayo Clinic Proceedings, 68, 642-651. https://doi.org/10.1016/S0025-6196(12)60599-0

[19] Nienaber, C.A., Fattori, R. and Mehta, R.H., et al. (2004) Gender-Related Differences in Acute Aortic Dissection. Circulation, 109, 3014-3021. https://doi.org/10.1161/01.CIR.0000130644.78677.2C

[20] Ince, H. and Nienaber, C.A. (2007) Diagnosis and Management of Patients with Aortic Dissection. Heart, 93, 266-270. https://doi.org/10.1136/hrt.2005.078550

[21] Hagan, P.G., Nienaber, C.A., Isselbacher, E.M., et al. (2000) The International Registry of Acute Aortic Dissection (IRAD): New Insights into an Old Disease. JAMA, 283, 897-903. https://doi.org/10.1001/jama.283.7.897

[22] Morello, F., Piler, P., Novak, M. and Kruzliak, P. (2014) Biomarkers for Diagnosis and Prognostic Stratification of Aortic Dissection: Challenges and Perspectives. Biomarkers in Medicine, 8, 931-941. https://doi.org/10.2217/bmm.14.38

[23] Segreto, A., Chiusaroli, A., De, S.S. and Bizzarri, F. (2014) Biomarkers for the Di- 
agnosis of Aortic Dissection. Journal of Cardiac Surgery, 29, 507-511.

https://doi.org/10.1111/jocs.12358

[24] Park, I.W., Min, P.K., Cho, D.K. and Byun, K.H. (2008) Successful Endovascular Treatment of Iatrogenic Coronary Artery Dissection Extending into the Entire Ascending Aorta. Canadian Journal of Cardiology, 24, 857-859.

https://doi.org/10.1016/S0828-282X(08)70196-X

[25] Majithia, A. and Levy, M.S. (2014) Drug Eluting Stents in Primary PCI: Ready for Prime-Time? Catheterization and Cardiovascular Interventions, 84, 963-964. https://doi.org/10.1002/ccd.25672

[26] Bangalore, S., Amoroso, N., Fusaro, M., Kumar, S. and Feit, F. (2013) Outcomes with Various Drug-Eluting or Bare Metal Stents in Patients with ST-Segment-Elevation Myocardial Infarction: A Mixed Treatment Comparison Analysis of Trial Level Data from 34068 Patient-Years of Follow-Up from Randomized Trials. Circulation: Cardiovascular Interventions, 6, 378-390.

https://doi.org/10.1161/circinterventions.113.000415 


\section{Abbreviations}

ACS: Acute coronary syndrome

AHRQ: Agency for Healthcare Research and Quality

ANOVA: Analysis of variance

CT: Computed tomography

CVA: Cerebrovascular accidents

HCUP: Healthcare Cost and Utilization Project

IRAD: International Registry of Acute Aortic Dissection

LOS: Length of stay

LVEF: Left ventricular ejection fraction

MI: Myocardial infarction

MRI: Magnetic resonance imaging

NIS: Nationwide Inpatient Sample

NSTEMI: Non-ST-elevation myocardial infarction

OR: Odds ratios

PCI: Percutaneous coronary intervention

PVD: Peripheral vascular disease

STEMI: ST-elevation myocardial infarction

TTE: Transthoracic echocardiography

\section{Scientific Research Publishing}

Submit or recommend next manuscript to SCIRP and we will provide best service for you:

Accepting pre-submission inquiries through Email, Facebook, LinkedIn, Twitter, etc. A wide selection of journals (inclusive of 9 subjects, more than 200 journals)

Providing 24-hour high-quality service

User-friendly online submission system

Fair and swift peer-review system

Efficient typesetting and proofreading procedure

Display of the result of downloads and visits, as well as the number of cited articles

Maximum dissemination of your research work

Submit your manuscript at: http://papersubmission.scirp.org/

Or contactijcm@scirp.org 